\title{
Teaching Strategies Used by Mathematics Teachers in the Jordan Public Schools and Their Relationship with Some Variables
}

\author{
Mohammad AbdelWahab H. Hamzeh* \\ Faculty of Educational Sciences, Isra University, Amman, Jordan \\ *Corresponding author: mohd_0@hotmail.com \\ Received May 03, 2014; Revised May 10, 2014; Accepted May 14, 2014

\begin{abstract}
This study investigated the use of teaching strategies among Mathematics Teachers at the Public schools in Jordon, and its relationships with teachers' gender, experience, and scientific level. A stratified random sample of (75) teachers is drown. To assess the Teaching strategy use, a questionnaire with (51) items is developed. The results showed that the general level of using teaching strategies was moderate, while the level of the behavioral strategies used by the teachers was high; whereas the cognitive and affective strategies were moderate. The results also showed that there were no significant differences $(\alpha \leq 0.05)$ in the Teaching strategies use related to teachers' gender, But there were significant differences in the Teaching strategies use related to experience variable in the affective strategies domain in favor of the teachers with less than (5) years experience. The results also showed significant differences in the Teaching strategies use related to scientific level variable in favor of the post graduate teachers. The researcher recommends training mathematics teachers on using the teaching strategies.
\end{abstract}

Keywords: teaching strategies, mathematics teachers

Cite This Article: Mohammad AbdelWahab H. Hamzeh, "Teaching Strategies Used by Mathematics Teachers in the Jordan Public Schools and Their Relationship with Some Variables.” American Journal of Educational Research, vol. 2, no. 6 (2014): 331-340. doi: 10.12691/education-2-6-1.

\section{Background}

\subsection{Introduction}

The educational schemes of today are seeking to develop teachers through making them full aware of the different teaching strategies; since an efficient teacher is decided by his/ her ability of choosing the proper teaching and learning strategies through which the objectives of the lesson are achieved and its content is fully covered; and by which students are gives the ability to acquire the formerly set lesson objectives which precisely meet their needs. However, choosing the appropriate teaching and learning strategies is a complicated process ; it demands a deep thinking on the part of the teacher and the ability to make balance between the available strategies in the light of the many interrelated variables.

A teaching strategy is in essence a general plan which includes all the parts of the teaching situation; namely: the objectives, teaching methods, teaching aids and evaluation strategies. The aforementioned parts are actually the activities a teacher does in the class for the purpose achieving the lesson's objectives. Teaching strategies are basically based on kinds of patterns and theories that are called "Learning Theories". Such theories are classified into three categories; they are: behavioral, cognitive and affective [19].
In the last few years, much attention was paid to the cognitive and effective strategies while behavioral strategies - which enjoyed much domination over the fields of education in the last decades - gained less attention. This is due to the attention paid increasingly to developing the ability of acquiring knowledge in students through different methods and improving the different thinking manners in them more than concentrating on merely having knowledge. Knowledge is changeable, developing and increasing all the time in terms of fields and resources, hence the need to learn the methods that enable individuals and communities alike to choose that which suits them of it and make use of it effectively [20].

Modern Education states that a learner is a whole entity; the personality of whom is a combination of three main dimensions; namely: the mental - cognitive dimension, the effective - rational dimension, and the psychobehavioral dimension. Such a combination demands that educators should provide teaching strategies that serve improving these three dimensions that create an integrated personality in the end. This very goal could only be achieved through using different teaching strategies. Researches in this field brought out three main approaches each of which created its own strategies that suit every dimension; these approaches are: behavioral approach, cognitive approach and effective approach. Deeply studying these approaches, one could easily notice the clear integration between them -though there are differences in terms of theory and practical applications 
between them - since these approaches study the human soul as a whole [24].

Behavioral strategies used to enjoy much dominance in the theoretical heritage; they were considered as the strategies or strictly directed behaviors which could be measured and noticed The goal of such strategies is to rectify the unsuitable behaviors and hence making effort towards teaching the desirable ones [7].

The behavioral assumptions include a change in behavior that leads to change in thoughts and feelings. A learner could evaluate his/ her effectiveness through the change that appears in a certain behavior. Studies related to behavioral strategies shed the light on the importance of using the behavioral strategies by both the teacher and the learner as away of comprehending and learning the basics of enhancing, formatting, and deciding the desired behaviors and the way of evaluating results [22].

On the other side, cognitive strategies came to existence as a reaction to the dominance of the behavioral strategies. Cognitive strategies aim at developing the role of the cognitive processes on the side of the learner, unlike the behavioral strategies that concentrate on the outside measurable behaviors. Reference [7] defined cognitive strategies as the plans a learner uses in order to achieve the goal he/ she pursues. A learner, for instance, could learn the skill of summarizing a text through writing down all his notes then examine his comprehension of what he read.

Reference [9], on the other hand, defined cognitive strategies to be a group of techniques, principles or basis that are used to facilitate acquiring, processing, storing, and recalling information in a certain situation.

As for Reference [21], cognitive strategies refer to the successfully directed - performance plans, or producing systems that aim at decreasing the turbulence that could exist between the existing knowledge of a learner and the objectives he wants to achieve. These strategies include a set of activities that help in choosing the proper information, connecting the newly acquired information with the previously stored one, and creating a positive learning environment and maintain it.

While Reference [1] concentrated on defining the cognitive strategies more than defining learning strategies in general. They voiced that cognitive strategies are the ways, principles, and basis that facilitate the process of acquiring, combining, storing, and recalling information in variable situations besides being a major tool for learning skills such as reading, writing, inquiring, acquiring new vocabularies, thinking, and solving problems.

Cognitive strategies could also be defined as the ways by which information is dealt with by symbols, and then stored and recalled. They are also defined as the way by which information is organized for the sake of decreasing the possibility of complication, or the process of combining information within one's knowledge structure in the brain for using it later [4].

Reference [18] defines teaching strategies to be certain activities a teacher does for the purpose of making learning process easier, quicker, funnier, more self directed, more effective, and more pushing towards new situations (Oxford, 1990).

Due to the lack of attention paid to the effective and social sides of a learner by both the behavioral and cognitive approaches; a third approach in the field of psychology came into existence. This approach calls for respecting a learner's abilities and humanizing the process of learning, it also calls for paying much attention to the learner's effectiveness state. This is indeed the humane approach; in which psychological reactions are considered of the most important factors which contribute in providing peaceful psychological health that paves the way towards achievement. This approach enhances developing learner's abilities in the classroom and hence the possibility of succeeding in dealing with others and enjoy an effective and successful life [5].

Psychology researches suggest that emotional reactions are of great importance in the process of learning from different angles; from one angle, they work as determiners for a set of factors some of which are: the nature of learning a certain subject, the tendencies towards the learned subject, the nature of the facts and information available on the subject, and the period a learner could save the information [2].

Those learning a certain subject could comprehend it without necessarily having certain attitudes towards it. This comprehension, however, would mean nothing to them till psychological reactions are formed towards it. Simply speaking, facts are of no use for the brain till we feel they are as such. A learning that lacks psychological reactions is an incomplete learning [11].

Studies related to effective approach show that teaching a learner psychological and social proficiencies at early stage affect their abilities of organizing their reactions and solving problems after having deep thinking in them. This would surely help them confront the difficulties that hinder their developing and hence the ability to cope with different situations and protect them from the pressure that they could face in their effective stages. The results that came out from the modern researches in the field of brain provided educators with valuable information in the fields of teaching and learning. It has become crystal clear that the necortex is the centre point for thinking for the learner, while the amygdalate is the centre point for reactions. Results also show that the development of these points' functions was taken by some scientists as a criterion when dealing with effective cleverness for amygdalate function verses to the general cleverness [10].

Using the teaching strategies successfully requires deep knowledge of when and how a teacher or a learner should apply them. The following steps show how a strategy is taught [19]:

- Correlate between the strategy and the task or the situation: at this stage a strategy is correlated with the task students would do; students could afterwards expand the circle of using the strategy in different real life situations. This stage enables students to participate in the learning process in the right direction from the beginning.

-Specifying the objective: This encourages students be engaged in the teaching process; since specifying objectives enhances students' motivation and attention towards stimulants that are to be learned.

- Modeling the strategy: This stage is considered an important teaching style in which the strategy moves through organized steps of procedures.

- Recalling the strategy: At this stage students should be able to explain the way the steps of the strategy move on easily; since at this stage, students are supposed to be well 
acquainted with the strategy through the previous stage which the teacher executed earlier with his students.

- Practicing the strategy: When students use the strategy for the first time, it should be suitable to their cognitive level and the nature of the task assigned to them.

Teaching strategies and their usage create great challenges for mathematic teachers in specific since the nature of mathematics comprises a set of interrelated minor skills. Mathematic teachers should create variable environments and they are the ones responsible for managing them the thing that makes taking the proper decision on the proper strategy to be used so difficult [1].

The tendencies mathematic teachers have, the way they acquire the minor skills, and the role of mathematics in modern life are all of the factors that affect in deciding which of the strategies suitable for teaching lessons of mathematics to choose. Those who adopt the constructional view that the most effective way of teaching mathematics is the one that provides students with the chance to relate their previous experiences with the one they are being taught. They believe that such experiences have great role in easing students' comprehension process. They also stress the important role of the social interactions that accompany the learning process which - according to them - have much importance over the product ; hence, they prefer using strategies like the group work, brain storming, plays, alternate learning, role playing and strategies of the like [23].

Perhaps the most important issue in the field of teaching mathematics especially in the first four grades, is the inability of mathematic teachers to use variety of teaching strategies in teaching mathematical skills, with all what these strategies include of questions and performance training and variety of analytical and constructional- analytical processes which provide students with the opportunities to learn the behavioral signs related to the skill learned, in an organized and effective manner within the social contexts and real life situations. Though teaching mathematics with all the needed skills still lies on the shoulders of mathematic teachers, it should also be lied on the shoulders of all teachers alike through using them in variety of teaching situations within different teaching contents [23].

Though it is of great important to adopt the integrative approach in activating students' role, most of the primary grades' teachers lack the ability to engage the interrelated and connected processes in mathematical skills with the teaching situations from one side and investing what students have of certain acquired experiences in favor of learning the rest of the related skills the thing that led to negative approaches towards using the integrative approach and other similar strategies [6].

The current study gains importance from the following considerations:

-The researcher expects that the results of the study would shed light on the teaching strategies that the mathematics teachers' are missing though such strategies help students engage in an affective learning process.

-As far as the researcher knows, this study is the first of its kind that aims at identifying the teaching strategies used by the mathematics teachers in the city of Amman Jordan in the light of the variables: Teacher's gender, experience, and qualifications.
-The study is of great use for the teachers and those who design curricula to know the teaching strategies mathematics teachers use.

-The study participates in developing mathematics curricula and its teaching strategies.

-The study is of great help for other researchers to develop other studies that are complementary to this study.

\subsection{Problem of the Study}

The researcher noticed -during his work in college, his visits to mathematics teachers, and his observations on the pre graduate students training in schools- that the majority of Teachers use the traditional teaching strategy that concentrate on the behavioral pattern depending on no clear framed teaching strategies and procedures when engaging in the teaching process.

Accordingly, teachers should take into consideration students' cognitive and effective ways of learning that help them develop positive and affective teaching patterns at the same time. This requires that a teacher should give more space for him self to think about which of the teaching strategies would fit more with the learners' properties, the nature of mathematics and teaching patterns, and at the same time go along with the accelerated information development in the different fields.

This very thing motivated the researcher to try to know more about the strategies mathematics teachers use and their relationship with some variables.

The study also shows students' weakness in mathematics which could be due to the teaching strategies teachers mathematics use. Students have always complain of the abstract nature of mathematics, and of the strategies used in teaching it to them which in no way help them develop a deep understanding to the subject; it depends instead on memorizing and dictation the thing that kills the motivation to learn in them. Using different teaching strategies properly in the classroom increases students' acquiring of knowledge [12].

\section{Purpose of the Study}

This study seeks to achieve the following objectives:

1 - Determining the teaching strategies that are most used by mathematics teachers in the Jordanian public schools.

2 - Determining whether there are differences in the level of using the teaching strategies by mathematics teachers due to the gender.

3 - Determining whether there are differences in the in the level of using the teaching strategies by mathematics teachers due to variations in teachers' expertise.

4 - Determining whether there are differences in the in the level of using the teaching strategies by mathematics teachers due to variations in teachers' qualifications.

\subsection{Questions of the Study}

The study attempts to answer the following questions: 1 - What teaching strategies are most used by mathematics teachers in the Jordanian public schools?

2- Is there a statistically significant difference $(\alpha \leq 05$, in the level of using the teaching strategies by mathematics teachers that are due to the gender? 
3 - Is there a statistically significant difference $(\alpha \leq 05$, In the level of using the teaching strategies by mathematics teachers that are due to variations in teachers' expertise?

4 - Is there a statistically significant difference $(\alpha \leq 05$, in the level of using the teaching strategies by mathematics teachers that are due to variations in teachers' qualifications?

\section{Terms of the Study}

- Teaching strategies: The procedures or activities teachers and students perform in the teaching -learning situation for the purpose of achieving the assigned teaching and learning objectives. Such teaching strategies are based on theories that are called Learning Theories which are classified into three schools: The behavioral, the cognitive, and the social.

- Teachers of mathematics: Are well qualified teachers appointed by the Jordanian Ministry of Education to teach mathematics; and they are the chosen sample of this study. These teachers work in the public schools in different directorates in the city of Amman in the year 2012-2013.

\section{Literature Review}

The researcher has examined many of the previous studies related to the subject matter; the following is a review of those studies.

Reference [25] aimed at examining the effect of the tow variables, the comprehension learning strategy and gender, in using the strategies used in teaching language at the University in Iran. The sample consisted of 54 male and female students studying the English Literature at Molem Education University in Iran. Three tools were used to gather data: TOFEL Test, Schmitt questionnaire for learning language; the questionnaire examined five kinds of strategies: (resolution, social, memory, cognition, beyond cognition), and recognition learning questionnaire. The study brought out of the following results: there are significant differences in recognition learning strategy students use and the strategies used in learning a language. The study also shows that the most used strategy by students is beyond recognition strategy then comes the resolution strategy, cognitive strategy, memory strategy, and finally the social strategy.

In Reference [2], strategies used in learning the English language were examined within a time of four semesters at Jadara University in Jordan. The sample consisted of 45 male and female students studying English at Jadara University. And in order to give accurate evaluation of the learning strategies; Oxford list was used with its six domains. Another study outcome is that using the learning strategies in learning the English language was so high in most of the list domains. Beyond knowledge strategy came first followed by the social then the knowledge strategy, the effective, the cognitive strategy and finally the memory strategy. As for the most used strategy for the sample students was: " I should concentrate to whoever speaks English, evaluate my progress in English, scan the text, read it again with more concentration, ask for others' help when I need it, repeat saying or dictating a word or a paragraph many times to memorize it, and find many ways to practice the language and learn it. The study also showed that there are no significant differences in using the strategies that are due to students' gender. On the other hand, there were significant differences due to the semesters taken in favor of the third and fourth semesters.

In Romania, Reference [13] executed a study on the effect of the learning strategies and the level of awareness of the beyond knowledge on the academic achievement for university students. The sample consisted of (202) male and female students who study psychology in two different universities in Romania. Weinstein's and others' list (1988) was used for assessing the level of using the learning strategies. The list consisted of (77 items each of which followed by five alternatives. The items are distributed amongst four measurements: skill, desire, motivation, and self organization. The results showed that the most used strategies by the sample were using metaphoric language, using extra words, organization, logic thinking skills, linking the new knowledge with that stored in memory, and making advantage of the learning aids. Another result was that the strategies most used in learning were as ordered: processing information strategies, teaching aids, self assessment, motivation, worry, concentration, and finally time management.

In Indonesia Study [15], aimed at knowing the strategies most used by high school students. The sample consisted of 170 male and female students studying in two different high schools. The researchers used a questionnaire they developed in the light of Oxford classification strategies for learning the English language. Study results showed that the strategies most used by the students are: frequent revision, repeating the new vocabularies, imitation, rehearsing language sounds, watching English programs, paying attention to mistakes one makes and try to avoid them, thinking of making more progress, and self rewarding. Having analyzed the domains the six strategies are used in, and having compared between them, one domain was found to be so much used namely beyond knowledge strategies. As for the rest of the five domains - Memory, cognitive, compensatory, social, and effective - they were used with lower frequencies.

Study [12] aimed at knowing the teaching strategies language teachers use and their effect on students' achievements. The sample consisted of (12) male and female teachers training at institutions for preparing teachers in Nineveh, Iraq. These teachers teach the Arabic language, Kurdish and English for first grade students studying at the institutions. Each three teachers belong to the same institution. In order to achieve the aims of the study, the researchers used Tuckman tool which consists of four pivots (creativity, power, behavior and warmth); each of which consists of (14) items. The study results showed that teachers of Arabic use successful strategies reaching $71 \%$; while teachers of Kurdish reached $61 \%$; whereas teachers of English reached 65\%.

Another study [17] that aimed at identifying the factors that have effect university students' decision on choosing their own learning strategies. The sample consisted of (75) female and male students of different nationalities studying at Ohio university. Oxford list (1990) for teaching strategies was used in the study. The study results showed that students use social and beyond 
knowledge strategies in a high level; while effective and memory strategies were used less. The results also showed that there are significant differences in choosing and using teaching strategies due to gender, age, and cultural background.

Study [3] aimed at knowing to what level teachers of Islamic Education at high schools in Jordan use the cognitive teaching strategies. In order to achieve that, an observation card was established consisting of the following domains: problem solving, directed discovery, and advance organization. The study was implemented on a sample of (30) teachers. The study results showed that teachers of Islamic Education in Jordan use the cognitive strategies on a high level. The results also showed that there are no significant differences in using such strategies due to teacher's qualifications and expertise.

General Comments on the previous studies:

From the previous brief presentation of the studies the following observations can be made:

- The results that came out from most studies showed that the strategies most used was the cognitive one ; while the behavioral, the effective, and the social strategies were used much less [3,17,25].

- study [2] results showed that the strategy most used was : the effective followed by the cognitive and finally the behavioral. On the other hand, study [15] showed another order: the behavioral, the cognitive and then the effective strategy.

- Some studies examined the effect of gender on using teaching strategies; there were no significant differences in using strategies due to difference of students' gender [2]. The results of other studies showed that there are significant differences in choosing and using teaching strategies that are due to gender, age, and cultural background [17].

- Some studies showed that there are no significant differences in using cognitive teaching strategies by teachers which are due to teachers' qualifications and expertise [3].

This study; however, tries to examine the teaching strategies used by mathematics teachers in public schools in Jordan from the teachers point of view and their relation to the variables of gender, expertise, and qualifications.

\section{Method}

\subsection{Study Methodology and Procedures}

In this study, the descriptive methodology, one of comparative survey studies, is adopted since it suits the objectives of the study very well.

A survey of the strategies a sample of mathematics teachers in Amman, Jordan, teaching in public schools, use was executed. The level of using these strategies was compared to the variables of gender, expertise, and qualifications.

\subsection{Study Population and Sample}

The study population consists of all teachers of mathematics working in public schools in Amman, Jordan, the number of whom reached (320) male and female teachers [16].

The study sample consisted of (75) male and female teachers chosen randomly from primary public schools in Amman as clarified in Table 1.
Table 1. Distribution of the sample according to the Variables of major Gender and expertise and Qualifications

\begin{tabular}{|c|c|c|c|}
\hline \multicolumn{2}{|r|}{ Variables } & number & Percentage \\
\hline \multirow{3}{*}{ Gender } & males & 35 & $47 \%$ \\
\hline & Female & 40 & $53 \%$ \\
\hline & Total & 75 & $100 \%$ \\
\hline \multirow{4}{*}{ Expertise } & Less than (5) years & 20 & $27 \%$ \\
\hline & From (5) to (10) years & 32 & $43 \%$ \\
\hline & More than (10) years & 23 & $30 \%$ \\
\hline & Total & 75 & $100 \%$ \\
\hline \multirow{4}{*}{ Qualifications } & $\mathrm{BA}$ & 42 & $56 \%$ \\
\hline & Diploma & 22 & $29 \%$ \\
\hline & MA or PHD & 11 & $15 \%$ \\
\hline & Total & 75 & $100 \%$ \\
\hline
\end{tabular}

\subsection{Data Collection Instrument}

In order to achieve the aim of the study, Questionnaire was developed making use of previous related studies [12], [15]. The researcher also made use of twenty teachers' answers on an open question about the strategies they use in teaching different school subjects.

The questionnaire, in its primary stage, consisted of (65) items distributed on three domains; the behavioral strategies, the cognitive, and the effective strategies. Having taken the opinions of the counselors, some of the items were modified, others were eliminated till the questionnaire reached its final picture with (51) items distributed on three domains:

The first domain: The behavioral strategies, consisting of (15) items.

The second: The cognitive strategies, consisting of (21) items.

The third: The effective strategies, consisting of (15) items.

In the questionnaire, the teachers would specify their level of agreement over the paragraphs raised in the questionnaire in a five-level Likert scale (strongly agree, agree, neutral, disagree, and strongly disagree). Five points were assigned for (Strongly Agree), four for (agree), three for (neutral), two for (disagree) and one for (strongly disagree).

In order to verify the tool validity, it was presented to five members of the teaching staff in Education Sciences College and three teachers working in Amman Third directorate to verify how suitable the items are for each domain and how much they represent them. In the light of the opinions of those counseled, some of the items were modified and others were omitted.

To make sure of the tool reliability, it was examined using two methods: Test - Retest method and Cronbach Alpha method. The questionnaire was applied on a sample other than the study sample consisting of 20 male and female teachers. Two weeks later, the same questionnaire was applied on the same sample. The reliability factor for the three domains - behavioral, cognitive, and the effective - reached in order: $(0.64,0.73$, and 0.75$)$, the total degree reached (0.85). In Cronbach - Alpha, the reliability factor reached in order as follows: $(0.68,0.78$, and 0.79$)$ and the total degree was (0.89).

\section{Results and Discussion}

\subsection{Statistical Treatment}

For the analysis of the results of the study sample, the researcher depended on filling the paragraphs of the 
questionnaire in special tables, and applying the following statistical measures:

- Descriptive measures: The mean, standard deviation, and the percentage for the purpose of describing grades distribution of the study sample statically in accordance with the study variables.

- Test (T) applied on two independent samples for the purpose of examining any significant differences in using teaching strategies with relation to the gender variable.
-Analyzing the differentiation of the first grade for the purpose of examining any significant differences in using the teaching strategies with relation to the expertise and qualification variables.

- Shefi test for post comparisons between mean couples.

- Cronbach-Alpha for calculating tool stability using the internal consistency method.

- Pearson's Relation Coefficient for calculating tool stability using stability method.

Table 2. Means, standard deviations, ranks, and grade for using teaching strategies by the sample

\begin{tabular}{|l|l|}
\hline No & Paragraph \\
\hline First domain: Behavioral Strategies. \\
\hline
\end{tabular}

\begin{tabular}{c|l}
3 & The teacher provides the student with information regarding his answer' accuracy all the time \\
\hline 13 & Tea
\end{tabular}

\begin{tabular}{cll}
\hline 13 & Teacher trains his students on distinguishing between different characteristics of the same concept
\end{tabular}

1 Teacher uses specific questions that have specific answers

11 Teacher helps his students imitate desired models

2 Teacher awards students for his right answer

4 Teacher uses direct presentation to provide students with information

9 Teacher cares about rectifying students' undesired behaviors

10 Teacher neglects undesired behaviors in the teaching - learning situations

$\begin{array}{lll}7 & \text { Teacher dissembles the teaching - learning material into specific tasks that need specific responses }\end{array}$

8 Teacher depends on criteria in evaluating his students

14 Teacher trains students on learning simple behaviors till they reach to the complicated behavior

15 Teacher eliminates any undesirable stimuli after student does the correct behavior

\begin{tabular}{|l|l}
5 & Teacher trains students to determine the objectives they want to achieve
\end{tabular}

6 Teacher makes advantage of the contract procedures he does with his students for the purpose of achieving the teaching - learning tasks.

12 Teacher provides students with a chance to apply new knowledge in new real life situations. Domain Total

Second domain: Cognitive Strategies.

17 Teacher begins with presenting main ideas of the topic at the beginning of the class.

18 Teacher ends reaching - learning situation with connecting the lesson parts together.

28 Teacher encourages students to verify information and facts before giving judgments.

34 Teacher moves from the abstract to the examples

19 Teacher begins the teaching - learning situation with presenting a problem to students

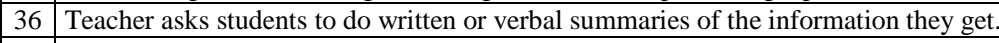

27 Teacher trains students to plan, observe, and evaluate their teaching activities

33 Teacher guides students to references such as dictionaries, encyclopedias, internet sites, ...etc.

25 Teacher trains students on generating unified answers for the stimulator raised for them

\begin{tabular}{ll}
29 & Teacher gives students a chance to generate new concepts \\
\hline 32 & Teach's cognitie tach
\end{tabular}

32 Teacher's cognitive teaching strategies harmonize with students' learning strategies

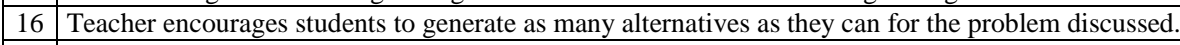

20 Teacher uses problem solving strategy in the teaching situation

30 Teacher facilitates for students make use of the procedures that organizes memory potentials

(symbolizing information)

$\begin{array}{lll}21 & \text { Teacher gives students enough time to question and investigate to the desirable objective. }\end{array}$

26 Students tend to generate new information through making comparison between their previous knowledge and new

26 one

22 Teacher ends teaching - learning situation with clarifying diagrams suitable for students

\begin{tabular}{ll}
23 & Teacher makes use concept maps during the teaching - learning process. \\
\hline 24 &
\end{tabular}

24 Teacher takes part in training students on generating original responses for the stimulus presented to them.

35 Teacher begins with examples up to the concept in the teaching - learning situation.

31 Teacher helps students identify their own learning methods. Domain total

Third domain: Effective strategies.

40 Teacher allows students to have more clarifications and explanations on a certain stimulus.

\begin{tabular}{l|l}
41 & Teacher supports students' sympathy towards others \\
\hline 48 & Teacher heps sudens have confidence in thenselves \\
\hline
\end{tabular}

48 Teacher helps students have confidence in themselves

\begin{tabular}{lll}
\hline 43 & Teacher encourages students to interact positively amongst themselves \\
\hline 49 & Teacher teach stents
\end{tabular}

49 Teacher teaches students the way to identify their points of strength and weakness

47 Teachers trains students to refer to their success or failure to own capabilities

50 Teacher strengthens leadership in his students

\begin{tabular}{lll}
37 & Teacher applies group work in the class to serve desired objectives \\
\hline
\end{tabular}

46 Teacher makes students take part in different roles in the teaching - learning situation.

51 Teacher takes part in improving students' ability to control their reactions.

38 Teacher distributes different teaching - learning tasks on students.

39 Teacher lets students have their own conversations positively.

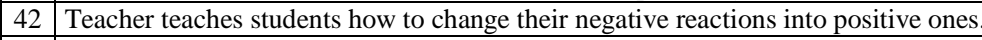

$\begin{array}{lll}44 & \text { Teacher trains students to solve their problems in a comfortable way. }\end{array}$

$\begin{array}{lll}45 & \text { Teacher gives students chance to initiate different debates amongst them. }\end{array}$ Domain Total

Total

\begin{tabular}{|c|c|c|c|}
\hline mean & S.D & Rank & grade \\
\hline 4.22 & 1.13 & 1 & high \\
\hline 3.94 & 1.19 & 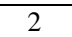 & high \\
\hline 3.88 & 1.027 & 3 & high \\
\hline 3.82 & 1.07 & 4 & high \\
\hline 3.77 & 0.92 & 5 & high \\
\hline 3.71 & 1.15 & 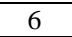 & high \\
\hline 3.63 & 1.29 & 7 & high \\
\hline 3.60 & 1.19 & 8 & high \\
\hline 3.51 & 1.10 & 9 & high \\
\hline 3.40 & 1.02 & 10 & hediun \\
\hline 3.17 & 0.99 & 11 & nediur \\
\hline 3.14 & 1.1 & 2 & nediun \\
\hline 2.94 & 1.03 & 13 & hediur \\
\hline 2.70 & 0.95 & 14 & mediu \\
\hline 2.67 & 1.11 & 15 & nediu \\
\hline 3.47 & 0.09 & & High \\
\hline 30 & 1.19 & 4 & High \\
\hline 4.12 & 15 & & High \\
\hline 34 & 0.99 & & figh \\
\hline 3.82 & 1.19 & & High \\
\hline 3.70 & 1.19 & 5 & High \\
\hline 3.65 & 1.10 & & High \\
\hline 3.62 & 1.027 & & High \\
\hline 3.50 & 1.15 & 0 & High \\
\hline 3.29 & 1.13 & 10 & edium \\
\hline 3.24 & 1.29 & & ed \\
\hline 3.22 & 1.29 & 12 & Ted \\
\hline 3.13 & 1.10 & 13 & Yediur \\
\hline 3.10 & 1.07 & 11 & ediur \\
\hline 3.07 & 1.027 & 14 & Mediur \\
\hline 2.90 & 0.92 & 15 & Tediu \\
\hline 2.82 & 1.02 & 17 & Medi \\
\hline 2.81 & 99 & & Mediu \\
\hline 2.76 & 13 & & ediu \\
\hline 2.63 & 0.95 & & ediu \\
\hline 2.61 & 1.027 & & \\
\hline 2.30 & 1.11 & 21 & \\
\hline 3.26 & 0.10 & & Mediu \\
\hline 3.77 & 1.027 & & igh \\
\hline 3.57 & 1.15 & & igh \\
\hline 3.97 & 1.15 & & ligh \\
\hline 3.43 & 1.19 & & High \\
\hline 3.41 & 0.99 & 5 & High \\
\hline 3.22 & 1.02 & & ediu \\
\hline 3.2 & & & \\
\hline 3.11 & 1.13 & & \\
\hline 3.10 & 1. & & \\
\hline 3.02 & 1.1 & 10 & \\
\hline 2.80 & 1.29 & & 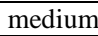 \\
\hline 3.00 & 1.19 & & ATdi \\
\hline 2.94 & 0.99 & 1 & medi \\
\hline 2.40 & 1.13 & 14 & low \\
\hline 2.12 & 1.29 & 15 & low \\
\hline 3.1 & 0.09 & & \\
\hline 3.3. & 0.0 & & \\
\hline
\end{tabular}




\subsection{Results Related to the First Question and Their Discussion}

What are the teaching strategies most used by mathematics teachers in the Jordanian public schools, from the teachers' point of view?

To answer this question, the mean, standard deviation, the percentage, and the percentile grade for each of the questionnaire items, the total grade, and the grades of the three domains were calculated as is clarified in Table 2. And in order to measure the level of using teaching strategies by mathematic teachers, the deviation used in Reference [17] was used depending on the means; as follows: (1.00-2.60) low usage level, (2.61 -3.40) medium usage level, (3.41 - 5.00) high usage level.

From Table 2, it could be noticed that the general level of using the teaching strategies by teachers of mathematics is medium; the general mean reached (3.31). As for the different kinds of teaching strategies, the behavioral strategies reached a very high level while the cognitive and effective strategies reached medium level with slight variance between them in favor of the cognitive strategies.

Table 2 also shows that (9) of the behavioral strategies - that is \%60 - were used intensively; while the other (6) strategies - that is $\% 40$ - were of medium usage. As for the cognitive strategies; (8) of them - that is \%38 - were used intensively; while the other (12) strategies - that is \%57 - were of medium usage; one strategy - \%5- only was of low usage. As for the effective strategies, the number of the strategies that were used intensively was (5) - that is \%33, (8) were of medium usage - that is \%54 -, whereas (2) strategies were used in a low manner that is $\% 13$.

The results that came out of the study are due to some factors, some of them are the following: for mathematics teachers, using behavioral strategies is much easier than other strategies and the curriculum itself includes so many behavioral strategies to which teachers feel to be bound. Social education institutions, such as the family and school, play a great role in this matter; they adopt the radical manner in their way of teaching and hence the great usage of the behavioral strategies. The systems and policies followed in the public schools have also clear role in the hierarchal decision making process.

These results are consistent with the ones that came out of the Study [15] that show that the behavioral strategies were most used followed by the cognitive then the effective ones.

The results of this study ; on the other hand, oppose that which came out of the other studies $[3,13,25]$; the results of these studies show that the cognitive strategies were the most used followed by the behavioral then the effective ones with low level use.

The results of this study also oppose that which came out of study [2]; which show that the effective strategies were the most used followed by the cognitive then the behavioral ones.

\subsection{Results Related to the Second Question and Their Discussion}

Results connected to the second question: Are there any significant differences at $(0.05 \geq \alpha)$ in using teaching strategies by mathematics teachers that are due to teacher's gender?

In order to answer this question, the mean and the standard deviation were calculated for the grades recorded for male and female teachers in the questionnaire; the $(\mathrm{T})$ test was used on two independent samples in order to identify the significant differences between the means; Table 3 clarifies the results of the calculations.

Table 3. The results of the $T$ test with the significant differences between the means for using the teaching strategies with relation to teacher's gender

\begin{tabular}{|c|c|c|c|c|c|c|}
\hline Strategy Domain & gender & No. & mean & Standard deviation & $\mathrm{T}$ value & Significance \\
\hline \multirow{2}{*}{$\begin{array}{l}\text { Behavioral } \\
\text { strategies }\end{array}$} & Male & 35 & 3.60 & 5.11 & \multirow{2}{*}{1.510} & \multirow{2}{*}{0.243} \\
\hline & female & 40 & 3.34 & 4.20 & & \\
\hline \multirow{2}{*}{$\begin{array}{l}\text { Cognitive } \\
\text { strategies }\end{array}$} & Male & 35 & 3.31 & 5.68 & \multirow{2}{*}{1.475} & \multirow{2}{*}{0.291} \\
\hline & female & 40 & 3.22 & 5.26 & & \\
\hline \multirow{2}{*}{$\begin{array}{l}\text { Effective } \\
\text { strategies }\end{array}$} & Male & 35 & 3.23 & 6.26 & \multirow{2}{*}{0.316} & \multirow{2}{*}{0.075} \\
\hline & female & 40 & 3.15 & 5.65 & & \\
\hline \multirow{2}{*}{$\begin{array}{l}\text { Total } \\
\text { Grade }\end{array}$} & Male & 35 & 3.38 & 5.68 & \multirow{2}{*}{0.090} & \multirow{2}{*}{0.975} \\
\hline & female & 40 & 3.24 & 5.04 & & \\
\hline
\end{tabular}

From Table 3, it is clear that the difference between the males and female means in their total grades that came out of the questionnaire is not significant; the $(\mathrm{T})$ result was only (0.090) and the level difference was (0.975) which is more than (0.05). It is also clear that there are no significant differences around $(0.05 \geq \alpha)$ regarding the level of using the teaching strategies whether behavioral, cognitive, and effective strategies due to difference in gender.

The former result could be interpreted to the teachers'whether males or females- knowledge of the various Patterns of the teaching-learning strategies; this knowledge was gained through training and expertise the teachers went through in addition to the training courses with which the Ministry of Education provides them.
This result goes in parallel line with the result that came out of study [2] which showed no significant differences that are due to students' gender in using the strategies. On the other hand, the study result in question opposes the one that came out of study [17] which showed that there are significant differences in choosing and using teaching strategies that are due to gender, age, and cultural background variables.

\subsection{Results Related to the Third Question and Their Discussion}

Are there significant differences at the level $(0.05 \geq \alpha)$ that are due to teacher' expertise in using teaching strategies by mathematics teachers? 
In order to answer this question, means and standard deviations for the teachers' total grades on the questionnaire were calculated for each of the three domains within the three kinds of expertise as shown in Table 4.

Table 4. The number of teachers, means, and standard deviations on the teaching strategies according to teacher's expertise

\begin{tabular}{|c|c|c|c|c|c|c|c|c|c|}
\hline \multirow{2}{*}{ Experience } & \multirow{2}{*}{ No. } & \multicolumn{2}{|c|}{ Behavioral strategies } & \multicolumn{2}{c|}{ Cognitive strategies } & \multicolumn{2}{|c|}{ Effective Strategies } & \multicolumn{2}{c|}{ Total Grade } \\
\cline { 3 - 11 } & & Mean & Standard Deviation & Mean & Standard Deviation & Mean & Standard Deviation & Mean & Standard Deviation \\
\hline Less than 5 years & 20 & 3.40 & 5.13 & 3.36 & 4.42 & 3.50 & 5.36 & 3.42 & 8.74 \\
\hline From 5 to 10 years & 32 & 3.46 & 4.25 & 3.24 & 3.50 & 3.30 & 4.25 & 3.33 & 6.41 \\
\hline More than 10 years & 23 & 3.54 & 5.05 & 3.18 & 4.76 & 3.26 & 4.43 & 3.32 & 10.74 \\
\hline Total & 75 & & & & & & & & \\
\hline
\end{tabular}

From Table 4, teachers with experience less than five years got the highest mean, followed by the teachers with experience between 5 to 10 years and finally teachers with more than 10 years. In order to verify that there are significant differences between the means of the teachers regarding using the teaching strategies, the ANOVA analysis was used. Table 5 shows the results of this analysis.

Table 5. Results of ANOVA analysis for significant differences between the means for using teaching strategies in relation to teachers' experiences

\begin{tabular}{|c|c|c|c|c|c|c|}
\hline Domain & Variance source & Squares sum & D.F & SS & F value & Significance \\
\hline \multirow{3}{*}{ Behavioral strategies } & Between groups & 180.93 & 2 & 36.19 & \multirow{3}{*}{8.252} & \multirow{3}{*}{0.462} \\
\hline & Within groups & 1880.52 & 72 & 6.38 & & \\
\hline & Total & 2061.45 & 74 & & & \\
\hline \multirow{3}{*}{ Cognitive strategies } & Between groups & 1195.23 & 2 & 236.66 & \multirow{3}{*}{20.160} & \multirow{3}{*}{0.171} \\
\hline & Within groups & 1638.64 & 72 & 5.55 & & \\
\hline & Total & 2833.87 & 74 & & & \\
\hline \multirow{3}{*}{ Effective strategies } & Between groups & 472.44 & 2 & 150.49 & \multirow{3}{*}{6.157} & \multirow{3}{*}{0.042} \\
\hline & Within groups & 2074.61 & 72 & 7.03 & & \\
\hline & Total & 2547.22 & 74 & & & \\
\hline \multirow{3}{*}{ Total Grade } & Between groups & 5215.56 & 2 & 1043.11 & \multirow{3}{*}{8.342} & \multirow{3}{*}{0.232} \\
\hline & Within groups & 12457.19 & 72 & 42.23 & & \\
\hline & Total & 17672.75 & 74 & & & \\
\hline
\end{tabular}

Table 5 shows that the $(\mathrm{F})$ value for the teaching there are no real differences between the means of the behavioral, cognitive, and effective strategies together with the total grade, the results were as follows : $(8.252$, $20.160,6.157,8.342)$ all of which indicate no significant differences at $(0.05 \geq \alpha)$ to the exclusion of the effective strategies ; the $(\mathrm{F})$ value of which indicates the existence of significant differences at $(0.05 \geq \alpha)$. This indicates that

teachers' grades that are due to experience in relation with the total grade. For the purpose of identifying the square means that Include significant differences in the effective strategies; Sheffi's post comparisons test was used. Table 6 clarifies the analysis test results.

Table 6. Sheffi's test results for post comparisons in the field of effective strategies in accordance with experience

\begin{tabular}{|c|c|c|c|}
\hline Experience & Less than 5 years & Between 5 to 10 years & $* 5.40$ \\
\hline Less than 5 years & & & More than 10 years \\
\hline Between 5 to 10 years & & & -6.39 \\
\hline More than 10 years & & & \\
\hline * The difference is significant at $(0.05 \geq \alpha)$ & \\
\hline
\end{tabular}

Table 6 shows that there are significant differences in the effective strategies, between the mathematic teachers who have less than (5) years, and those who have between (5) to (10) years and those who have more than (10) years, Referring to the means shown in Table 4, the differences are in favor of the teachers who have experience less than (5) years. This might be due to these teachers' age; those who are young believe in students' freedom and try to enhance students' confidence and allow them to express it more in their learning.

These results - in relation with experience - oppose the ones that came out of study [3] which showed that there are no significant differences in teachers' usage for the teaching strategies that are due to difference in experience.

\subsection{Results Related to the Forth Question and Their Discussion}

Are there significant differences at $(0.05 \geq \alpha)$ in using teaching strategies by mathematics teachers that are due to teachers' qualifications ?

In order to answer this question, means and standard deviations for the total grades in the questionnaire for each of the three domains in connection with the teachers' qualifications were calculated - as shown in Table 7. 
Table 7. Number of teachers, means, and standard deviations in accordance with qualifications

\begin{tabular}{|c|c|c|c|c|c|c|c|c|c|}
\hline \multirow{2}{*}{ Level } & \multirow{2}{*}{ number } & \multicolumn{2}{|c|}{ Behavioral strategies } & \multicolumn{2}{|c|}{ Cognitive strategies } & \multicolumn{2}{|c|}{ Effective strategies } & \multicolumn{2}{|r|}{ Total grade } \\
\hline & & Mean & Standard Deviation & Mean & Standard Deviation & Mean & Standard Deviation & Mean & Standard Deviation \\
\hline BA & 42 & 3.51 & 5.12 & 3.12 & 4.57 & 3.15 & 4.88 & 3.26 & 10.02 \\
\hline High Diploma & 22 & 3.35 & 6.09 & 3.21 & 4.36 & 3.18 & 4.50 & 3.25 & 10.41 \\
\hline Ma or PHD & 11 & 3.55 & 3.99 & 3.45 & 4.63 & 3.24 & 3.69 & 3.41 & 10.56 \\
\hline
\end{tabular}

Table 7 shows that the means of the teachers' grades in the three fields and in the total grade of the questionnaire. the questionnaire related to teaching strategies differ In order to verify whether these differences are significant according to the teacher's university degree; this is so in or not, ANOVA Analysis Test. Table 8 shows the results.

Table 8. Results of ANOVA Analysis Test for significant differences in means for the level of using the teaching strategies in relation with teachers' degree

\begin{tabular}{|c|c|c|c|c|c|c|}
\hline Domain & Variance source & Squares sum & Freedom grades & Square mean & F calculated value & Difference level \\
\hline \multirow{3}{*}{ Behavioral strategies } & Between groups & 52.36 & 2 & 17.45 & \multirow{3}{*}{0.821} & \multirow{3}{*}{0.488} \\
\hline & Within groups & 1958.47 & 72 & 6.59 & & \\
\hline & Total & 2010.83 & 74 & & & \\
\hline \multirow{3}{*}{ Cognitive strategies } & Between groups & 170.52 & 2 & 56.84 & \multirow{3}{*}{2.792} & \multirow{3}{*}{0.045} \\
\hline & Within groups & 2290.01 & 72 & 7,71 & & \\
\hline & Total & 2460.53 & 74 & & & \\
\hline \multirow{3}{*}{ Effective strategies } & Between groups & 124.11 & 2 & 41.37 & \multirow{3}{*}{1.781} & \multirow{3}{*}{0.165} \\
\hline & Within groups & 2471.53 & 72 & 8.32 & & \\
\hline & Total & 2595.11 & 74 & & & \\
\hline \multirow{3}{*}{ Total Grade } & Between groups & 622.16 & 2 & 207.39 & \multirow{2}{*}{1.521} & \multirow{2}{*}{0.214} \\
\hline & Within groups & 15308.01 & 72 & 51.54 & & \\
\hline & Total & 15930.23 & 74 & & & \\
\hline
\end{tabular}

The results shown in Table 8 show that the $(\mathrm{F})$ calculated value for the three teaching strategies domains and the total grade were as follows in order : $(0.821,2.792$, $1.781,1.521)$; they are all considered as insignificant differences to the exclusion of the cognitive strategies result which is considered as significant difference at $(0.05 \geq \alpha)$.

In order to identify the means that have significant differences in relation with the cognitive strategies, Sheffi's Test for post comparisons was executed. Table 9 shows the results of the test.

Table 9. Seffi's Test for post comparisons in the field of cognitive strategies in relation with the teacher's qualification

\begin{tabular}{|c|c|c|c|}
\hline Qualification & BA & High Diploma & MA\&/ or PHD \\
\hline BA & & -2.11 & $* 4.58$ \\
\hline High Diploma & & & $* 2.68$ \\
\hline MA\&/ or PHD & & & \\
\hline * The difference is at $(0.05 \geq \alpha)$ & \\
\hline
\end{tabular}

Table 9 clearly shows that there are significant differences at $(0.05 \geq \alpha)$ between the means of the grades of the teachers whose university degree is MA\&/ or PHD and those who have BA or high diploma. Referring to the means in Table 7, the differences are in favor of those teachers who have higher qualifications.

This is probably because they are more well acknowledged of the educational theories and their applications; the very thing that enables such teachers to comprehend more deeply the cognitive strategies and apply them through their studies. This would support their applying them in the educational process.

However, these results oppose the ones in study [3] which show no significant differences in teachers' usage of the teaching strategies that are due to difference in their qualifications.

\section{Recommendations}

Based on the results of the current study, the researcher recommends the following:

- Holding specialized courses for mathematics teachers and encourage them to use the different teaching strategies, especially the cognitive and the effective ones.

- Do more researches on the strategies used by teachers in other school subjects.

- Testing the effectiveness of the modern teaching strategies produced by the educational literature in the teaching - learning situations on different samples.

\section{References}

[1] Abu Jado, Salih. (2005). Learning Strategies and Application in Classroom. Amman: Education Institute Publications (UNRWA, UNESCO).

[2] Al-Jabali, M. (2012). “Language learning strategy use and concept development among Jordanian undergraduate English language majors”. International journal of Education, 4 (1), 161-180.

[3] Al-Keelanee, Al- Hakeem, Sameer. (2009). The level of Using Teaching Cognitive Strategies by Islamic Education Teachers in high school in Jordan. Al- Basair Magazine, 13 (1): 353-384.

[4] Ashman, F., Adrian \& Conway, F., Robert. (1997). Introduction Ltd, Pad stow, Cornwal. London, New York.

[5] Bintaş, J. (2008). Motivational qualities of Mathematical experiences for Turkish preserves kindergarten Teachers. International Journal of Environmental \& Science Education, 3(2), 46-52.

[6] Barling, J \& Slater, E. (2000). Transformational Leadership and Emotional Intelligence: An Exploratory Study of leadership. Organization Development. Journal, 21. (21), pp157-161. 
[7] Cakici, Y., Aricak, O. T. \& Ilgaz, G. (2011). "Can attitudes toward biology course and Learning strategies simultaneously predict achievement in biology". Eurasian Journal of Educational Research, 45, 31-48.

[8] Cesur, M. O. (2011). "A model explaining relationships between language learning strategies, learning styles and success in reading comprehension”. Hacettepe University Journal of Education, 41, 83-93.

[9] Day, Victoria P. (1994). Promoting strategic learning, retrieved July 12, 2002, from: www.EBSCO.com.

[10] Engel-Yager, B.; Durr, D. H. \& Josman, N. (2011). "Comparison of memory and meta-memory abilities of children with cochlear implant and normal hearing peers". Disability and Rehabilitation, 33 (9), 770-777.

[11] Jenesen, Eric. (1997). Brain Compatible Strategies. The Brain store, Inc, San Diago.

[12] Ibraheem, Abdullah; Abdulfattah, Shuaib; Humaid, Saddam. (2010). The Teaching Strategies Used by the Teachers of Languages and their Relation to Students Achievements. Primary Education College Research Magazine. 9 (4) : 1-23.

[13] Kallay, E. (2012). Learning strategies and Metacognitive awareness as predictors of academic achievement in a sample of Romanian second- year students. Cognition, Brain, Behavior- An Interdisciplinary Journal. 16 (3), 369-385.

[14] Livingston, J. A.(1997). Metacognition: An Overview. Retrieved June 10, 2005, from: http://www.gse.buffalo,edu/fas/shuell/cep564/Metacogn.htm

[15] Mattarima, K. \& Hamdan, A. R. (2011). Understanding students learning strategies as an input context to design English classroom activities”. International Journal of Psychological Studies, 3 (2) 238-248.

[16] Ministry of Education, (2011). Education Planning Department Publications. Central Press.

[17] Nguyen, N. \& Godwyll,F. (2010). "Factors influencing languagelearning strategy use of English learners in an ESL context". MidWestern Educational Research, 23 (4), 7-13.

[18] Oxford, R.I. (1990). Language Learning Strategies: What Every Teacher Should Know. New York: Newbury House Publisher.

[19] Pei-Shi, W. (2012). The effect of learning styles on learning strategy use by EFL learners. Journal of Social Sciences, 8 (2), 230-234.

[20] Pongsuwan, S., Hoksuwan, S., In-Udom, W., \& Chalakbang, W. (2011). "Development of an e-learning model based on the meaningful learning process through a constructivist theory". European Journal of Social Sciences, 24(4), 625-638.

[21] Schunk, D. (2000). Learning theories: An educational Perspective.(2nd ed). New Jersey: Prentice- Hall, Inc.

[22] Sternberg, J. \& Williams M. (2004).Educational Psychology. Allyn \& Bacon.

[23] Tobin, K., (1993).The Practice of Constructivism in Science Education, Lawrence Erlbaum Associates, Inc.

[24] Woolflolk, Anita (2002). Educational Psychology. Pearson Educational Company.

[25] Zokaee, Saeedeh; Zaferanieh, Elaheh; Naseri, Mahdieh. (2012). On the Impacts of Perceptual Learning Style and Gender on Iranian Undergraduate EFL Learners' Choice of Vocabulary Learning Strategies, English Language Teaching, 5(9): 138-143. 